\title{
Ground seed density patterns under conditions of strongly overlapping seed shadows in Abies alba Mill. stands
}

\author{
Jarosław G. Paluch
}

Received: 22 April 2010/Revised: 6 January 2011 / Accepted: 18 January 2011 / Published online: 12 February 2011

(C) The Author(s) 2011. This article is published with open access at Springerlink.com

\begin{abstract}
In three subsequent years, seeds were collected from 66 to 75 seed traps in three Abies alba stands that differed in vertical structure and the number of potentially reproducing trees. The objective was to compare empirical patterns of seed density with a random (Poisson) model, which assumes that seed density would be the same in every location, and a binomial negative model that is appropriate for over-dispersed data. The seed density patterns were tested for spatio-temporal independence. The effect of some dispersal variables (number of mother trees and seed fall seasons, dispersal distance, fecundity rate) on seed density pattern was studied in a simple simulation experiment. Several local stand density measures (stem density, basal area, distance-weighted indices, canopy openness) were also tested for their ability to predict local seed density. The Poisson model was rejected in all the stands studied, and a much better fit achieved using the binomial negative model. The simulation study revealed that random seed distribution may occur only at considerable dispersal distances, concave seed shadows, and at very low fecundity rates. The seed density patterns identified exhibited both spatial and temporal correlation, which can probably be linked to the arrangement of mother trees and variation in their seed output. To a minor degree, this seed density pattern also correlated with local stand density.
\end{abstract}

Keywords Local stand density - Seed bank - Natural regeneration $\cdot$ Seed dispersal kernel

Communicated by C. Ammer.

J. G. Paluch $(\bowtie)$

Department of Silviculture, University of Agriculture, A1. 29

Listopada 46, 31-425 Cracow, Poland

e-mail: jppaluch@pro.onet.pl

\section{Introduction}

Regeneration processes in forest ecosystems are highly stochastic, dependent on many factors both biotic and abiotic and can seldom be fully controlled. One important source of spatial variation in regeneration density is environmental heterogeneity, which affects both seed germination and the survival of emerging seedlings. Another source of such variation, albeit less apparent, is the pattern of seed dispersion, which is determined by the spatial pattern of reproductive adults and their seed outputs, seed shadows and disperser characteristics (Ribbens et al. 1994; Clark et al. 1998; Nuttle and Haefner 2005).

During the past decades, some advances have been made in methods for characterising seed dispersion patterns, extracting information from them about dispersal processes and building models (Clark et al. 1999; Nathan and Muller-Landau 2000; Greene and Calogeropoulos 2002; Wagner et al. 2004; Wälder et al. 2009). Nevertheless, reliable seed dispersal models are still sparse. The most frequently proposed phenomenological models, being functions of distance from the seed source, are simple to apply but difficult to generalise because their parameters bear no direct relation to particular characteristics of the plant or disperser. Mechanistic models, on the other hand, are more general and can predict seed dispersion patterns directly from the characteristics of plants and their dispersal agents (Andersen 1991; Kuparinen 2006); however, they are complicated to develop, parameterise and implement (Nathan et al. 2001; Schippers and Jongejans 2005). Likewise, information on seed appearance and seed dispersal has not yet been satisfactorily consolidated. Because of different genotypes, social position or shading, flowering and seed production varies within individual trees as well as among years within a population (e.g. Greene et al. 
2002; Greenberg 2000). These factors are very tedious to study, and therefore, its knowledge is meagre in forest trees. In effect, the spatio-temporal patterns of seed density and its importance to regenerative processes, except for some more detailed cases studied (e.g. Ribbens et al. 1994; Clark et al. 1998; Nuttle and Haefner 2005; Sagnard et al. 2007), remains still poorly understood.

Prior investigations have most often analysed the seed shadows of single trees (Kohlermann 1950; Greene and Johnson 1989; Guevara and Laborde 1993; Holthuijzen and Sharik 1985) or seed rain in border zones between closed stands and open/clear-cut areas (Greene and Johnson 1996; Dohrenbusch 1997; Johnson 1988). This, perhaps most general, knowledge is helpful overall for anemochoric species, which are mostly regenerated on larger open areas. Some authors have focused on seed rain in relatively large gaps (Burschel et al. 1985) or on stands that contain singly occurring individuals of one species among trees of other species (Stoyan and Wagner 2001; Sagnard et al. 2007; Wälder et al. 2009). However, there is still a paucity of data on seed dispersal patterns in mono-specific forest interiors characterised by many mother trees around which winds vary and windless conditions are quite frequent, i.e. in conditions under which most barochoric and "transitive" species are regenerated in shelterwood, irregular shelterwood systems and different forms of uneven-aged forests.

Disregarding seed dispersion pattern in mono-specific stands with many parent trees and overlapping seed shadows results partly from the belief that under such conditions variation in ground seed density is negligible and decreases additionally with the increasing number of seed seasons as a result of partly asynchronic seed production. However, in the face of well-documented variation in the fecundity of single parent trees (e.g. Greene et al. 2002; Greenberg 2000; Turner et al. 2007), such a belief may be quite misleading. Given small dispersal distances and a rapidly decreasing probability of seed fall with increasing distance from the parent, variation in ground seed density may be additionally enhanced by heterogeneity in local stand density, as for example in multi-layered forests or stands regenerated by an irregular shelterwood method. Moreover, seeding in a single year with favourable conditions for germination and early survival may turn out to be more crucial for the patterning of regeneration than the seed density cumulated over several less advantageous seasons. Therefore, even in mono-specific stands with many parent trees and overlapping seed shadows, ground seed density probably exhibits heterogeneity potential for forming irregular distribution of regeneration.

This investigation focused on the spatio-temporal pattern of ground seed density in relatively dense stands of Abies alba with random distribution of trees and strongly overlapping seed shadows. The main objective was to examine whether intra-stand ground seed density follows a hypothetical Poisson model that assumes the same density in every location and attributes eventual deviations to random effects. It was expected that the concordance between the Poisson model and the empirical seed density would increase when the stand density and the number of parent trees increased, and seed counts were cumulated over several seasons. These rather intuitive hypotheses were tested by comparing empirical seed counts monitored in three Abies alba stands with the appropriate Poisson models, as well as by using a simple model of seed dispersal, which approximated the effect of mother tree density, dispersal distance, fecundity rate and the number of seed seasons on intra-stand seed density variation.

A natural alternative to the Poisson model is a hypothesis that assumed over-dispersion of seed density. In such a case, further questions arise: whether seed rain intensity is related to local stand density (and implicitly number of parent trees) and which portion of its variation may be explained by different local stand density measures, whether seed density patterns exhibit spatial and/or temporal correlation attributable to variation in the local stand density, and whether this correlation deepens or, on the contrary, tends to decrease when seed counts are cumulated over several seed fall seasons. The present analysis attempts to tackle these issues by examining seed counts data collected during three successive seasons in one multilayered stand and two one-storeyed stands contrasted in stem density.

\section{Characteristics of species and study sites}

A long-living tree that reaches an age of 400-450 years and a height of $45 \mathrm{~m}$, silver fir occurs in the mountainous and upland regions of Middle and Southern Europe and belongs to the least light-demanding species among European dendroflora. Being a conifer species, silver fir produces winged, relatively heavy seeds (on average, 45-55 g per 1,000 dried, ready-to-store seeds, Suszka 1983) that spill out of its cones in October. Although seed fall is most intensive in October, in mono-specific stands, a considerable portion of the seeds $(25-45 \%$ according to unpublished author data) may be retained in the dense crowns of mother trees (during windless days) or their neighbours (during windy days) and fall later (secondary dispersal). Single seeds may still fall until May. Over a decade, two full masts and two partial masts with seed production between 40 and $70 \%$ of that in a full mast can be expected (Rohmeder 1972, pp. 57). According to Kohlermann (1950), under conditions of open space at wind speed 1.7, 2.7 and $5.9 \mathrm{~m} \mathrm{~s}^{-1}$ seeds of Abies alba Mill. dropped from a height of $14 \mathrm{~m}$ covered 26, 34 and $72 \mathrm{~m}$, on average, 
respectively. In Abies alba stands of basal area 39 and $26 \mathrm{~m}^{2} \mathrm{ha}^{-1}$, half of the seeds that were dropped from the tree tops (i.e. from a height of $29 \mathrm{~m}$ ) at an average wind speed of 0.6 and $2.5 \mathrm{~m} \mathrm{~s}^{-1}$ (measured $2 \mathrm{~m}$ above the forest canopy) landed at distances less than 7.2 and $8.5 \mathrm{~m}$ in the denser stand and 7.9 and $14.7 \mathrm{~m}$ in the looser stand, respectively (unpublished author data). However, these latter figures refer only to primary dispersal; that is, they take into account only those seeds that were swept from cones and reached the ground directly. Secondary dispersal of seeds trapped in tree crowns may differ both in terms of the conditions that initialise the process and dispersal parameters. For instance, under the same wind conditions $\left(2.5 \mathrm{~m} \mathrm{~s}^{-1}\right)$, seeds that dropped from a height of 29 and $20 \mathrm{~m}$ covered distances of 7.9 and $5.6 \mathrm{~m}$ on average, respectively (unpublished author data).

For this study, three stands were selected from among those included in a research programme on the regeneration of A. alba, one in the Carpathian foothills (OS-I, $49^{\circ} 57^{\prime} \mathrm{N}, 20^{\circ} 27^{\prime} \mathrm{E}$ ) and the other two in the Sadecki Beskid (MS, $49^{\circ} 24^{\prime} \mathrm{N}, 20^{\circ} 58^{\prime} \mathrm{E}$ ) and Pieniny (OS-III, $49^{\circ} 26^{\prime} \mathrm{N}$, $20^{\circ} 27^{\prime} \mathrm{E}$ ) (southern Poland). These stands, none of which had undergone silvicultural treatments for at least 10 years, differed particularly in the stand density, the number of potentially reproducing firs and vertical structure (see Table 1, for their general characteristics). Although the preliminary tests of inter-event distances (Diggle 1983, pp. 11-12) revealed small deviations from complete spatial randomness, exact Monte Carlo tests suggested acceptance of this hypothesis at a solid confidence level.
In the lower montane belt zone of the study region, the vegetation period is ca 190-200 days, average annual temperature is $6-8^{\circ} \mathrm{C}$ and annual precipitation is $850-950 \mathrm{~mm}$, 550-600 mm of which occurs between April and September (Hess 1965). In the region's foothills, the vegetation period is somewhat longer, ca 215 days, and precipitation does not exceed $700 \mathrm{~mm}$. Snow cover is present for 95-105 days in higher elevations and for 75 days on average in the foothills. In this region, westerly and south-westerly winds are most frequent, and the fraction of windless days is relatively high (20-50\%) (Lorenc 2005). Between October and December 2005-2007, when the majority of Abies seeds fall, average wind speed under conditions of open space was $2-2.5 \mathrm{~m} \mathrm{~s}^{-1}$, and the fraction of westerly and south-westerly winds was $22-35 \%$ and $26-30 \%$, respectively (R. Jastrzębski, personal communication). Nevertheless, because of the diversified terrain, wind conditions in the stands studied might deviate from these general characteristics.

\section{Method}

Fieldwork

For all plots, records were made of the stem coordinates (exact to $0.1 \mathrm{~m}$ using a compass and ultrasonic distance meter), species, diameters at breast height of all live trees $(\geq 7.0 \mathrm{~cm}$ in diameter) and the heights of a part of the trees. The trees in buffer zones of $50 \mathrm{~m}$ in width were also mapped.

Table 1 Stand characteristics

\begin{tabular}{|c|c|c|c|}
\hline \multirow[t]{2}{*}{ Characteristics } & \multicolumn{3}{|l|}{ Stand } \\
\hline & OS-I & OS-III & MS \\
\hline $\operatorname{Size}^{\mathrm{a}}(\mathrm{m})$ & $112.5 \times 75.0$ & $162.5 \times 50.0$ & $152.5 \times 60.0$ \\
\hline Altitude (m) & 300 & 650 & 725 \\
\hline Aspect & SEE & SWW & SWW \\
\hline Slope $\left(^{\circ}\right)$ & 6 & 22 & 15 \\
\hline Age (years) & 90 & 125 & $40-150$ \\
\hline Stem density $\left(\mathrm{d}_{1.3} \geq 7 \mathrm{~cm}\right)\left(\mathrm{N} \mathrm{ha}^{-1}\right)$ & 382 & 537 & 715 \\
\hline Stem density $\left(\right.$ Abies, $\left.\mathrm{d}_{1.3}>20 \mathrm{~cm}\right)\left(\mathrm{N} \mathrm{ha}^{-1}\right)$ & 214 & 494 & 224 \\
\hline Basal area $\left(\mathrm{d}_{1.3} \geq 7 \mathrm{~cm}\right)\left(\mathrm{m}^{2} \mathrm{ha}^{-1}\right)$ & 34 & 70 & 35 \\
\hline Basal area $\left(\right.$ Abies, $\left.\mathrm{d}_{1.3}>20 \mathrm{~cm}\right)\left(\mathrm{m}^{2} \mathrm{ha}^{-1}\right)$ & 24 & 67 & 24 \\
\hline$\%$ Abies in basal area $(\%)$ & $73^{\mathrm{b}}$ & 98 & 95 \\
\hline Mean diameter $(\mathrm{cm})$ & 31 & 39 & 21 \\
\hline Mean height ${ }^{\mathrm{c}}(\mathrm{m})$ & 27.3 & 31.0 & 29.0 \\
\hline Vertical structure & One-storeyed & One-storeyed & Multi-storeyed $^{\mathrm{d}}$ \\
\hline
\end{tabular}


The research was conducted in three subsequent years, which in the region contrasted in the yield of Abies alba seeds (high in 2005 and very low in 2007). In every stand, at the end of August 2005, 100 seed traps (with a catchment area of $0.173 \mathrm{~m}^{2}$ ) were placed horizontally at ground level in a stratified random scheme, and their coordinates were recorded. In the stratified random sampling, the study region was divided into equal non-overlapping squares, from each of which one location was selected at random. The same distribution of traps was preserved every year. The trap bottoms were made from a synthetic, dark, waterpermeable fabric whose $10-\mathrm{cm}$ high brims were of strong fibreboard. To camouflage the traps, their bottoms were covered with a thin layer of forest floor. The fir seeds were collected from the traps three to four times each season and always in the last 10 days of April 2006, 2007 and 2008. The seeds collected from every undisturbed trap were then counted in the laboratory and, based on visual examination and cut tests, divided into sound seed capable of germination (hereafter, sound seeds) and empty or damaged seeds (henceforth, damaged seeds). Only locations for which complete data were available for all 3 years (2005, 2006 and 2007) were considered for analysis (some traps had been damaged), 68 in the OS-I stand, 66 in the OS-III stand and 75 in the MS stand.

In the stands studied, no evidence emerged of increased predator activity, controlled for by placing perforated transparent plastic saucers containing 5 seeds with characteristically rounded wings near the seed traps and visiting them every 2-3 weeks in autumn and spring-when snow cover was absent-to check the number of seeds predated by rodents and birds. Except for isolated cases, no losses were registered.

\section{Characteristics of local canopy density}

To characterise canopy openness above the traps (i.e. the fraction of open sky, unobstructed by vegetation, in a specified region of the canopy), hemispherical images were taken in every trap location during July-August 2007. All these photographs were acquired under overcast conditions, from an above-ground height of $1.2 \mathrm{~m}$, using a Nikon E4500 camera with Nikon FC-E8 fisheye converter fixed on a tripod and a universal o-mount with a northfinder.

The hemispheric photographs were analysed with the WinSCANOPY Pro 2006a program (Régent Instruments, Inc.) using the manufacturers' camera and lens specifications and the pixel classification method based on grey levels (with thresholds ranging from 240 to 250 for a 0-255 scale). For every trap location, canopy openness was determined for three rings given by the zenith angles $0-10^{\circ}, 0-20^{\circ}$ and $0-90^{\circ}$ (hereafter, Canopy 10, Canopy20, Canopy90).
Distribution fitting and spatio-temporal dependence

Basic statistics were determined to characterise the empirical distributions of seed density (separately for sound and damaged seeds), and then the Poisson and negative binomial models were fitted, and their significance checked by Kolmogorov-Smirnov and Anderson-Darling tests (in comparison with the Kolmogorov-Smirnov test, the latter gives more weight to the tails, is more sensitive, but has the disadvantage that critical values must be taken from the tables). Whereas in the Poisson distribution, the variance is equal to the mean, the negative binomial distribution includes an additional parameter that can be used to adjust the variance independently of the mean (Dobosz 2004). To check whether spatial variation differs for sound and damaged seeds (e.g. as a result of inter-tree variation or smaller dispersal distances of empty seeds), the basic statistics were determined separately for these categories.

To test the inter-seasonal independence of the seed shadows, Pearson correlation coefficients were computed between seed counts in 2005, 2006 and 2007 and tested for significance using Monte Carlo tests (5,000 simulations, two-tailed tests). Because positive relations between years could result from differences in local stand density, this effect was controlled for by also computing partial correlation coefficients and testing their significance. In this procedure, one of the seed count vectors was permuted, while the vector of local basal area data (here BA3, as explained below) and the second seed count vector were held constant with respect to each other. To weaken the effects of spatial correlation, the correlation coefficients were tested using a moving blocks method with a block radius of $10 \mathrm{~m}$ rather than with simple permutation (Efron and Tibshirani 1993, pp. 99-101).

To characterise the seed density's spatial dependence, a variogram was estimated using the data from all seed traps and the robust estimator $2 \bar{\gamma}(h)$ recommended by Cressie (1991, pp. 40)

$$
\begin{aligned}
2 \bar{\gamma}(h(l))= & \left\{\frac{1}{|N(h(l))|} \sum_{N(h)}\left|Z\left(s_{i}\right)-Z\left(s_{j}\right)\right|^{1 / 2}\right\}^{4} \\
& /\left(0.457+\frac{0.494}{|N(h(l))|}\right),
\end{aligned}
$$

where $Z\left(s_{1}\right), \ldots, Z\left(s_{n}\right)$ are the spatial data observed at spatial locations $\left\{s_{i}: i=1, \ldots, n\right\}$, the sum is over $N(h) \equiv$ $\left\{(i, j): s_{i}-s_{j}=h ; h \in T(h(l))\right\}$, the region $T(\mathrm{~h}(l))$ is a specified "tolerance" region around $\mathrm{h}(l)(2.5 \mathrm{~m}$ was assumed) and $|N(h)|$ is the number of distinct elements of $N($ h). Rational quadratic variogram models (Cressie 1991, pp. 61) were fitted to the log-transformed data 
$\left(Z^{\prime}\left(s_{i}\right)=\log \left(Z\left(s_{i}\right)+0.5\right)\right)$ using an approximately weighted least squares criterion (Cressie 1991, pp. 96-97). The estimation was carried out only up to half the maximum possible lag and only using lags for which $|N(h)|>30$. The spatial variation in seed density was decomposed into small-scale variation (the so-called nugget effect obtained by interpolating the back-transformed variogram estimates at lags closest to zero) and large-scale variation (the backtransformed sill of the fitted variogram model). The lower the ratio of small-scale to large-scale variation, the stronger the spatial dependence in the data. Obviously, if the ratio approaches 1 , the spatial dependence disappears (i.e. the variation becomes independent of the spatial scale).

\section{Relations with local stand density}

Several distance-weighted and distance-independent local stand density indices were tested for their ability to predict ground seed density. However, in all computations of local stand density, only firs of $d_{1.3} \geq 20 \mathrm{~cm}$ were taken into account. Smaller individuals were ignored because, in the stands studied, such trees, mostly over-topped and with senescent crowns, only produced seeds sporadically (personal observation).

Firstly, the number of seeds in a seed trap $s_{i}$ was modelled as a simple, distance-independent linear function of a variable $X$ that describes the local stand density around the seed traps:

$s_{i}=b_{0}+b_{1} X_{i}$,

where $b_{0}$ and $b_{1}$ are parameters. This approach employs the following indices as local stand density measures: (1) canopy openness (Canopy10, Canopy20, Canopy90) (2) the number (henceforth, N2, N3, N4, N5) and (3) the basal area of firs growing within a radius $2 r, 3 r, 4 r, 5 r$ (henceforth, BA2, BA3, BA4, BA5, respectively), where $r=0.5 \sqrt{ }($ plot area/number of firs $)$ is an approximated, stand-specific, nearest-neighbour distance (in $\mathrm{m}$ ). To examine possible directional effects, a comparison was made of the correlations between the number of seeds and the number and basal area of firs growing within a $2 r, 3 r$, $4 r$ and $5 r$ radius in 8 azimuth sections 0-45 (NNE), 45-90 (NEE), .., 315-360 (NNW).

Secondly, an inverse modelling technique was used to assign weights to trees depending on their basal area and distance to the seed trap $s_{i}$. The inverse modelling methods rely on numerically intensive calculations of the likelihood of obtaining the observed data on seed dispersion pattern given a particular model that specifies seed shadows of the mapped seed sources. For comparison with the phenomenological seed dispersal model published by Sagnard et al. (2007), the weights were formulated using probability density (kernel) functions symmetric about the origin. In this approach, the number of seeds in the seed trap $s_{i}$ was modelled as the overall sum over the fecundity of each $j$ th tree (component $\alpha B A_{j}$ in the equation below) times the kernel function $f$, which assigns probability $\left(\right.$ per $\mathrm{m}^{2}$ ) that a seed has travelled a given distance $u_{i j}$ from the $j$ th tree:

$s_{i}=\sum_{j} \alpha B A_{j} f\left(u_{i j}\right)$.

In the above formulation, $B A_{j}$ denotes the basal area of the $j$ th tree, and $\alpha$ is a fecundity parameter that gives the number of seeds produced per each $\mathrm{cm}^{2}$ of basal area. To obtain the proper density functions (i.e. to fulfil the condition $2 \pi \int_{0}^{\infty} f(u) u d u=1$, which guarantees that each seed falls somewhere), the kernels must include a normalising factor. In this present analysis, however, although the kernel functions maximise the information obtained from the spatial arrangement and size of the trees, they are predicted on an assumption that seldom holds; namely that all the trees are simultaneously parents. Therefore, their relation to seed dispersal kernels, which attempts to describe "true" seed shadows from known parent tree locations and observed seed counts, is rather loose.

The analysis employed three kernel functions. The first kernel was the exponential function fitted by Sagnard et al. (2007) to Abies alba data using the inverse method (henceforth, INVmod):

$f(u)=\frac{\beta_{1}}{N} \exp \left[-\left(\frac{u}{\beta_{0}}\right)^{\beta_{1}}\right]$,

where $\beta_{0}, \beta_{1}$ are parameters, $N=2 \pi \beta_{0}^{2} \Gamma\left(2 / \beta_{1}\right)$ is the necessary normalising constant and $\Gamma()$ is the gamma function. The parameters assumed here, $\beta_{0}=0.981$ (re-calculated to align with the formulation used) and $\beta_{1}=0.461$, yield an intermediate curve in relation to the two kernels fitted by Sagnard et al. (2007) to the data from the 2 subsequent years. Because the adaptability of the Sagnard et al.'s kernel to the stands studied here was uncertain, two other kernel functions were fitted via inverse technique to the original data sets: a curve from the exponential family (formulated as above and henceforth, INVexp) and a log-normal function (henceforth, INVlog):

$f(u)=\frac{1}{N} \exp \left[-\frac{\left(\ln u-\beta_{1}\right)^{2}}{2 \beta_{0}^{2}}\right]$,

where $\beta_{0}, \beta_{1}$ are parameters and $N=(2 \pi)^{3 / 2} \beta_{0} u^{2}$ is again a normalising factor. It should be noted that the exponential function defines a monotonically decreasing curve, whereas the lognormal function allows to shift the maximum probability from the mother tree (i.e. it takes as its maximum $u=\exp \left(\beta_{1}-2 \beta_{0}^{2}\right)$ ), which may emulate the 
"skip distance" at dispersion from an elevated source. Because the research plots were located on slopes, it was also useful to include a correction that captures the asymmetry of the seed shadows in the uphill and downhill directions, $\hat{u}=u+(\Delta z \cdot u) / H$, where $u$ is the horizontal distance between the tree and the trap, $\Delta z$ is the difference between the trap's $z$-coordinate and the tree base and $H$ is the mean tree height (as in Table 1).

In the first stage, the model parameters $b_{0}, b_{1}, \beta_{0}$ and $\beta_{1}$ were obtained from 500 bootstrapped maximum likelihood estimates. The Poisson likelihood was assumed (Stanisz 2007, pp. 793), and the log-likelihood functions were minimised using the Nelder-Mead algorithm. If the buffer zone of a 50-m width was too narrow, a toroidal correction was used to avoid edge effects. To retain the spatial structure of the seed-count data, a moving blocks bootstrap was applied using a block length of $10 \mathrm{~m}$ (Efron and Tibshirani 1993, pp. 99-101). The parameter $\alpha$ was estimated directly from the field data as a quotient of mean seed density (per seed trap) and the stand basal area (in $\mathrm{m}^{2}$ )

In the second stage, the fitted models were compared using the deviance:

$D=-2 \ln \left(\frac{L_{m}}{L_{s}}\right)$

where $L_{m}$ is the likelihood of the tested model and $L_{s}$ is the likelihood of the saturated model, in which the predicted and observed seed counts are equal (Stanisz 2007, pp. 790). The calculation also incorporated McFadden's $R^{2}$ (likelihood ratio index) defined as.

$R^{2}=1-\left(\frac{\ln L_{m}}{\ln L_{P}}\right)$.

Here, $L_{P}$ is the likelihood that corresponds to the Poisson model, where predicted seed counts equal the sample mean. The deviance of the tested model against the Poisson model was then compared to a chi-squared distribution, with the number of degrees of freedom given as the difference in the numbers of parameters in the two models. In all cases, the likelihoods compared were means obtained from the 5,000 moving block bootstrap samples.

\section{Simulation experiment}

The relations between most important dispersal variables (mother tree density, dispersal distance, shape of dispersal curve, seed production) and the intra-stand seed density pattern were studied using a simple seed shadow model defined by Eq. 1. In a virtual forest with a given stand density constant and an area large enough to prevent border effects, trees were allowed to disperse seeds according to the exponential dispersal kernel (Eq. 2). The tree distribution was random with an inhibition imposed for distances below the nearest-neighbour distance for trees of over-average diameter. The diameter distributions of the mother trees, the seed production per individual and the dispersal distance were Gaussian with a standard deviationto-mean ratio of 0.3 . In the case of tree diameter, the distributions were truncated for values below two standard deviations from the mean to introduce a commonly occurring right-sided asymmetry. The mean seed production per individual was assumed to be proportional to the basal area of the mother trees (as in Eq. 1). Then, 500 simulations were run for 100 seed traps (with a $1-\mathrm{m}^{2}$ catchment area, distributed in a stratified random scheme analogous with that used in the stands studied) at different settings of the input parameters: mother tree density between 25 and 325 per ha, median dispersal distance between 5 and $35 \mathrm{~m}$, concave or convex at origin shape of dispersal kernel (parameter $\beta_{1}$ from Eq. 2 between 0.5 and 3.0) and seed production per individual between 1 and 10 seeds per year and $\mathrm{cm}^{2}$ of basal area. The range of these input parameters seems sufficiently wide to cover probable conditions in real Abies alba stands (e.g. Sagnard et al. 2007 estimated a median dispersal distance between 13.2 and $19.4 \mathrm{~m}$, a $\beta_{1}$ parameter about 0.5 and seed production per individual between 4.75 and 10.0 seeds per year and $\mathrm{cm}^{2}$ of basal area). They are thus very likely to illustrate the most important relations and tendencies. For every setting of the input parameters, the lowest and largest values of variance-to-mean ratio and standard deviation of seed count were preserved. At each simulation step, a rational quadratic variogram model was fitted to the simulated spatial data, and the small- and large-scale variations were estimated analogously to the empirical set.

To study hypothetical multi-annual seed dispersion patterns, several initial assumptions were made. First, the mean seed production per $\mathrm{cm}^{2}$ of basal area (parameter $\alpha$ in Eq. 1) was derived from a triangular distribution having a lower limit and a mode equal to 0.0 and an upper limit of 10.0. The number of mother trees was sampled from a normal distribution with a mean equal to $30 \alpha$ and a standard deviation equal to $7 \alpha$, which reflects the increased number of mother trees expected in years of higher seed output. It was also assumed that the probability of a tree producing seeds would be proportional to its basal area, meaning that larger trees can be expected to produce seeds more frequently. The 500 simulations for the 100 seed traps were then run for series of $2,3, \ldots, 10$ subsequent seasons, and the largest and lowest values of the variance-to-mean ratio and standard deviation of seed counts (cumulated over 2, 3,..,10 subsequent seasons) were again preserved. Nevertheless, it should be emphasised that because empirical knowledge on seed production and dispersal process is still insufficient, the 
model used here was based necessarily on purely arbitrary albeit rather likely assumptions (e.g. the Gaussian dispersal distance and seed production per individual and the mean annual seed production per $\mathrm{cm}^{2}$ of basal area derived from triangular distribution).

\section{Results}

\section{Empirical seed density pattern}

The number of seeds that fell annually during the 2005-2007 period successively decreased each year (Table 2), with the seed production in 2005 amounting to $46-65 \%$ of the total three-year production. For 2005, the proportion of damaged seeds was between 36 and 53\% but increased considerably over the subsequent years to a 2007 level of $83-89 \%$. Among the seeds categorised as "damaged", the greatest proportion (60-95\%) was due to abnormally developed and distorted seeds without any sign of damage by insects or other animals (data not illustrated).

The coefficients of variation calculated for seeds that fell during three seasons 2005-2007 were in the range of $0.30-0.50$ for all seeds and were comparable to those for the 2005 seed year. The coefficients of variation increased in 2007, when seed production was small. The variation in sound seed density was comparable to or insignificantly higher than the variation in damaged seeds. The seed distributions were characterised by high variance (the variance-to-mean ratio $>1$ ) and in that respect deviated markedly from the Poisson distribution (in which the ratio $=1$ ) $($ Table 2). For all stands, the Poisson model of seed density had to be flatly rejected $(P<0.001)$; however, the negative binomial model resulted in much better performance (Fig. 1), and in all the cases, the significance levels for Kolmogorov-Smirnov and Anderson-Darling tests were above 0.1. Overall, the empirical variance-tomean ratio did not depend upon the amount of seeds produced by the stands studied (Table 2).

Except for the OS-III stand (for 2006 vs. 2007), a significant positive correlation was found between seed densities in the subsequent years (correlation coefficients between 0.46 and 0.64) and between seed densities in 2005 and 2007 (Table 3). The analysis of the coefficients of partial correlation (in which local stand density was excluded) led to similar conclusions. A positive correlation was detected between the total number of fallen seeds and the number of sound seeds (with correlation coefficients between 0.58 and 0.91 and in the MS stand, for 2007 only, 0.36) (Table 3).

In many cases, the seed density exhibited distinct spatial dependence (Fig. 2). In 2005 (a good seed-crop year), seed density in all stands showed significant spatial dependence at scales below $30-40 \mathrm{~m}$ (in the OS-I and OS-III stands) or $10 \mathrm{~m}$ (in the MS stand). In the OS-I stand, the small-scale variation amounted to $14-35 \%$ of the large-scale variation and in the OS-III stands, to 24, 37 and $75 \%$ for 2005, 2006 and 2007, respectively. The proportion of small-scale variation to large-scale variation was largest in the MS stand (65-100\%). The variograms for sound seeds (data not illustrated) corresponded to those for all seeds pooled.

Empirical relations between seed density and local stand density

In many cases, incorporating local density variables increased prediction accuracy over that of the Poisson
Table 2 Seed density characteristics

\begin{tabular}{lllll}
\hline Characteristics & Year & OS-I & OS-III & MS \\
\hline No. of seed traps & - & 68 & 66 & 75 \\
Mean (min-max) & 2005 & $23.0(4-67)$ & $61.2(27-109)$ & $32.8(77-17)$ \\
(per seed trap) & 2006 & $20.1(4-69)$ & $26.5(5-86)$ & $22.9(2-82)$ \\
& 2007 & $7.1(0-37)$ & $7.0(0-41)$ & $10.2(0-38)$ \\
Variance-to-mean ratio & $2005-2007$ & $50.2(16-120)$ & $94.7(38-157)$ & $65.9(25-161)$ \\
& 2005 & 6.7 & 4.8 & 3.8 \\
& 2006 & 5.6 & 6.3 & 5.6 \\
Coeff. of variation & 2007 & 7.7 & 7.7 & 5.6 \\
& $2005-2007$ & 12.5 & 9.1 & 10.0 \\
& 2005 & 0.55 & 0.29 & 0.34 \\
& 2006 & 0.52 & 0.48 & 0.50 \\
& 2007 & 1.05 & 1.05 & 0.74 \\
Damaged seeds $(\%)$ & $2005-2007$ & 0.50 & 0.30 & 0.38 \\
& 2005 & 53 & 36 & 42 \\
& 2006 & 79 & 77 & 81 \\
\hline
\end{tabular}


Fig. 1 Example of seed density distributions and fitted Poisson (dashed line) and negative binomial models (solid line) in the OS-I stand
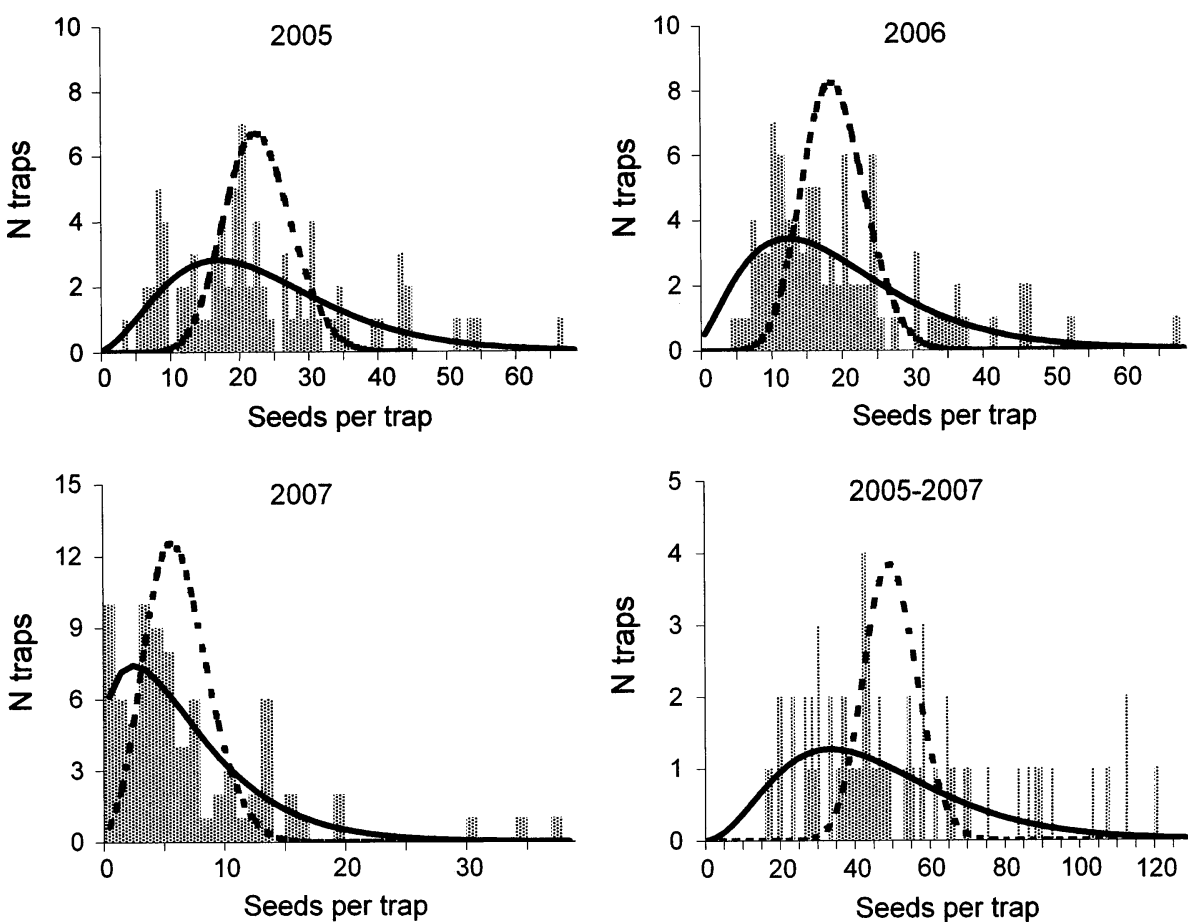

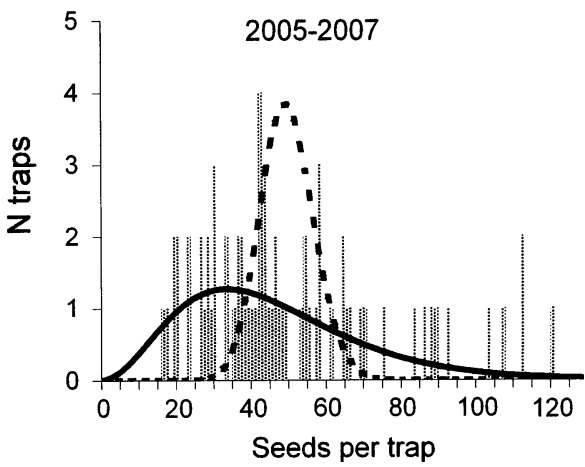

Table 3 Coefficients of correlation between seed densities in 2005 , 2006 and 2007

\begin{tabular}{|c|c|c|c|}
\hline Year & OS-I & OS-III & MS \\
\hline \multicolumn{4}{|l|}{ All seeds } \\
\hline \multicolumn{4}{|l|}{ Simple correlation } \\
\hline 2005 vs. 2006 & $0.64 * * *$ & $0.49 * * *$ & $0.57 * * *$ \\
\hline 2006 vs. 2007 & $0.46 * * *$ & 0.17 & $0.59 * * *$ \\
\hline 2005 vs. 2007 & $0.40 * *$ & $0.24 *$ & $0.48 * * *$ \\
\hline \multicolumn{4}{|l|}{ Partial correlation $^{\mathrm{a}}$} \\
\hline 2005 vs. $2006 / \mathrm{BA} 3$ & $0.56 * * *$ & $0.45 * * *$ & $0.51 * * *$ \\
\hline 2006 vs. $2007 / \mathrm{BA} 3$ & $0.40 * * *$ & 0.15 & $0.54 * * *$ \\
\hline 2005 vs. $2007 / \mathrm{BA} 3$ & $0.33 *$ & 0.22 & $0.43 * * *$ \\
\hline \multicolumn{4}{|l|}{ All vs. sound seeds } \\
\hline 2005 & $0.91 * * *$ & $0.89 * * *$ & $0.82 * *$ \\
\hline 2006 & $0.65 * * *$ & $0.57 * * *$ & $0.63 * * *$ \\
\hline 2007 & $0.60 * * *$ & $0.58 * * *$ & $0.36 * *$ \\
\hline
\end{tabular}

Values significant at the $0.05,0.01$ and 0.001 levels are marked with $*$, ** and ***, respectively

a The effect of local basal area (BA3) was excluded

model. The greatest improvement occurred in the OS-I stand data, whose pseudo- $R^{2}$ for best predictor (INVexp) was 0.64 (Table 4). The corresponding values were 0.34 for Canopy 20 in the OS-III stand, but only 0.12 for BA3 in the MS stand.

Nevertheless, the performance of these seed density predictors differed among stands. For instance, the best results for the OS-I stand were yielded by the INVexp and
INVlog; however, these kernels failed for another two stands, particularly the OS-III (Table 4). For the OS-III stand, the best prediction was achieved using the indices based on local canopy openness (Canopy20), whereas for the multi-layered MS stand the best results were given by the BA3 and BA4 indices. Overall, these results suggest that if one general variable is to be selected to describe local seed density, it should be the BA3, which turned out to be an acceptable predictor regardless of stand density and structure (Fig. 3). For the pure Abies stands (OS-III and MS), canopy openness yielded similar (MS stand) or even better (OS-III stand) results than local basal area. However, the local number of firs was a poorer predictor than basal area.

As shown by the slope coefficients $b_{1}$ given in Table 5, the seed counts tended to increase with the increasing local basal area. In the majority of the cases analysed, the seed counts correlated most strongly with the basal area and number of trees located in the SEE, SSW or SWW directions (Fig. 4) - that is, approximately against the prevailing winds-although in comparison with those for the local basal area integrated over all the trees, irrespective of directional location, the correlations were admittedly weak. The effect of local basal area was most pronounced for the OS-I stand (1.24 divided by the seed trap catchment area $0.173 \mathrm{~m}^{2} \approx 7$ seeds $/ \mathrm{m}^{2}$ per each $\mathrm{m}^{2} / \mathrm{ha}$ of local basal area), diminished for the OS-III stand (about 3 seeds per each $\mathrm{m}^{2} / \mathrm{ha}$ of local basal area) and was the weakest for the MS stand (about 1.5 seeds $/ \mathrm{m}^{2}$ per each $\mathrm{m}^{2} /$ ha of local basal area). The effect of canopy openness was significant only 
Fig. 2 Estimated variograms and fitted models for seeds collected in 2005 (triangles), 2006 (white circles) and 2007 (dark circles) $(h=5 \mathrm{~m})$

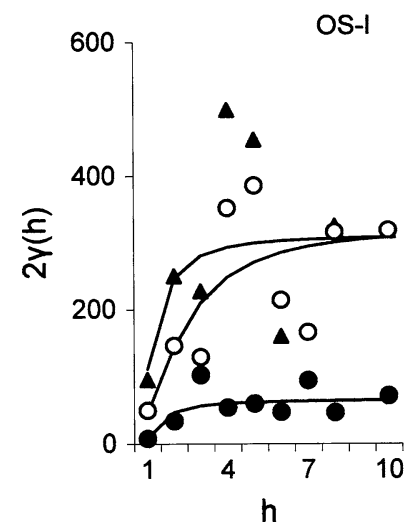

Table 4 Deviance $D$ and McFadden's pseudo- $R^{2}$ for the competing models of cumulative seed counts (2005-2007) based on different local stand density measures

\begin{tabular}{lllrlll}
\hline Index & \multicolumn{2}{l}{ Stands } & & & & \\
\cline { 2 - 7 } & OS-I & OS-III & \multicolumn{1}{l}{ MS } & \multicolumn{1}{l}{ OS-I } & OS-III & MS \\
& $D$ & & & $R^{2}$ & & \\
\hline N2 & 482 & 644 & 1,135 & 0.40 & 0.08 & n.s. \\
N3 & 478 & 617 & 605 & 0.41 & 0.11 & n.s. \\
N4 & 609 & 646 & 683 & 0.26 & 0.08 & n.s. \\
N5 & 690 & 642 & 494 & 0.14 & 0.08 & 0.09 \\
BA2 & 463 & 612 & 657 & 0.43 & 0.12 & n.s. \\
BA3 & 525 & 536 & 478 & 0.37 & 0.23 & 0.12 \\
BA4 & 712 & 539 & 480 & 0.15 & 0.22 & 0.12 \\
BA5 & 702 & 595 & 499 & 0.13 & 0.14 & 0.08 \\
Canopy10 & 760 & 499 & 513 & 0.08 & 0.28 & 0.06 \\
Canopy20 & 755 & 458 & 500 & 0.08 & 0.34 & 0.08 \\
Canopy90 & 826 & 579 & 502 & n.s. & 0.17 & 0.08 \\
INVmod & 571 & 735 & 1,011 & 0.34 & n.s. & n.s. \\
INVexp & 295 & 734 & 546 & 0.64 & n.s. & n.s. \\
INVlog & 304 & 964 & 555 & 0.63 & n.s. & n.s. \\
\hline
\end{tabular}

The pseudo- $R^{2}$ was given only for the models which confidence level against the Poisson model was $>0.95$. In the MS stand, for the indices BA6, BA7 and BA8, the deviance is 497, 497 and 510, respectively

for the OS-III stand, for which a $1 \%$ increase in canopy openness produced about a 7 seeds $/ \mathrm{m}^{2}$ decrease in seed density.

Simulated seed density patterns

As illustrated by the simulation experiment, dispersal distance had a significantly stronger effect on the variance-tomean ratio than did mother trees density or fecundity rate (Fig. 5). Specifically, the variance-to-mean ratio decreased exponentially as the dispersal distance increased, but showed no change as the number of mother trees decreased. Rather, it tended to increase slowly as the fecundity rate increased. The shape of the seed shadow
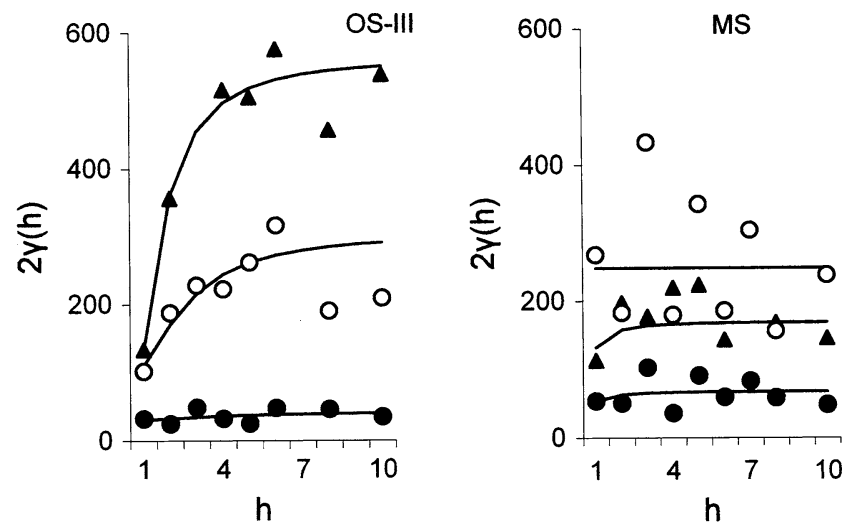

(concave or convex depending on the $\beta_{1}$ parameter value) also had only a minor effect on the variance-to-mean ratio. For the range between 0.5 and 3.0, the ratio tended to increase slowly as the $\beta_{1}$ value increased. However, an increasing number of mother trees and an increase in dispersal distance and fecundity rate reduced the coefficient of variation of seed density (Fig. 5). The variance-to-mean ratio for cumulative seed density tended to increase as the number of consecutive seed fall seasons increased.

The seed density patterns obtained in the simulation experiment were characterised by very clear spatial dependence (Fig. 6). The ratio of small-scale variation to largescale variation tended to increase as the number of mother trees increased but to decrease with increases in fecundity rate, dispersal distance and seed shadow convexity.

\section{Discussion}

In the stands studied, both the annual and 3-year seed dispersion patterns deviated significantly from that expected under the assumption of random seed rain. First, the seed density distributions were mono-modal but strongly over-dispersed with respect to the Poisson model. In fact, the simulation experiment showed (Fig. 5) that given reliable median dispersal distances for Abies alba seeds (e.g. $6.5-10.5 \mathrm{~m}$ estimated in this study, 13.2-19.4 m estimated by Sagnard et al., 2007 and 5.6-14.7 estimated by the author, unpublished data), the seed density distribution is likely to be strongly over-dispersed. The Poisson seed distribution could occur only when dispersal distance is high, seed shadows are very concave and seed output is low. Second, although the analysis found no link between over-dispersion and annual seed production, it did show a higher variance-to-mean ratio for seed density cumulated over three seasons 2005-2007 than for single years.

Thus, the Poisson distribution is inappropriate for modelling either annual or multi-annual seed density in Abies alba stands. Clark et al. (1998), who found similar 
Fig. 3 Relation between local basal area (BA3) and seed counts per seed trap cumulated over 2005-2007. Parameters of the regression models are given in Table 5
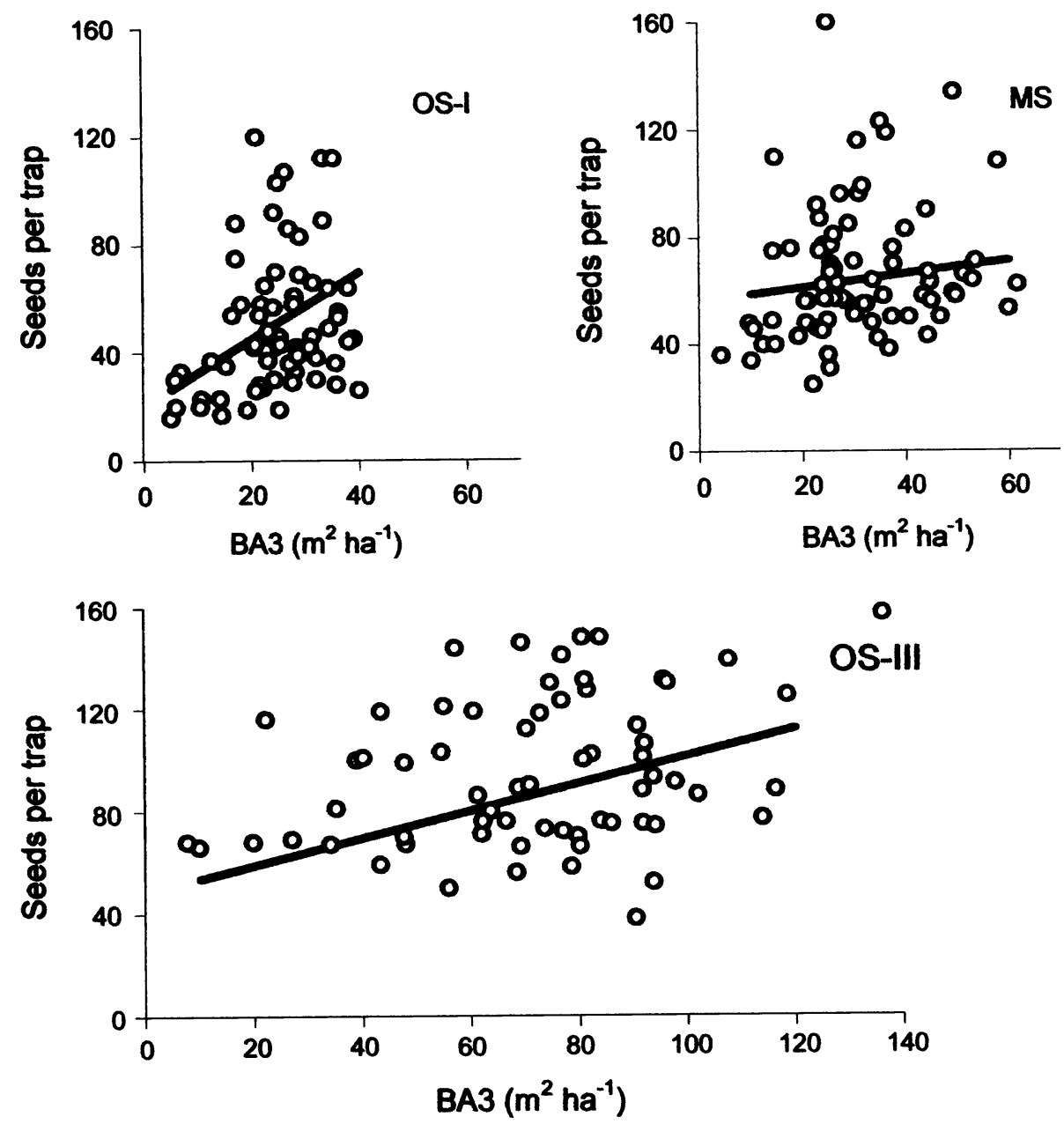

Table 5 Parameters, coefficients of correlation $(r)$ and standard error of estimation (SEE) for the selected models of seed density per seed trap cumulated over 2005-2007

\begin{tabular}{llcccr}
\hline Predictor & Stand & Parameter $b_{0} / \beta_{0} \pm$ SE & Parameter $b_{1} / \beta_{1} \pm$ SE & Parameter $\alpha$ & SEE \\
\hline BA3 $\left(\mathrm{m}^{2} / \mathrm{ha}\right)$ & OS-I & $20.27 \pm 7.44$ & $1.24 \pm 0.32$ & - & 23.9 \\
& OS-III & $48.31 \pm 18.85$ & $0.53 \pm 0.20$ & - & $0.44^{* * *}$ \\
& MS & $56.32 \pm 3.34$ & $0.25 \pm 0.75$ & - & $0.37 * *$ \\
Canopy20 (\%) & OS-I & $48.76 \pm 11.13$ & $-0.02 \pm 0.39$ & - & 0.24 \\
& OS-III & $118.16 \pm 15.18$ & $-1.25 \pm 0.38$ & - & 28.9 \\
& MS & $64.37 \pm 4.92$ & $-0.18 \pm 0.17$ & - & 26.8 \\
INVexp & OS-I & $5.22 \pm 0.12$ & $1.40 \pm 0.21$ & 11.8 & $0.53 * *$ \\
\hline
\end{tabular}

Model descriptions are given in the text

Values significant at the $0.05,0.01$ and 0.001 levels are marked with $*$, ** and ***, respectively

clumped patterns of seed density in multi-species stands, recommended the use of a negative binomial distribution, which, albeit at the cost of an extra parameter, introduces over-dispersion into the model. In fact, the negative binomial model performed well for the Abies alba stands studied here.

The production of diaspores shows some periodicity, conditioned not only by external factors controlling the induction of flowering (temperature, light availability, water and nutrient supply) but also by physiological source-sink relationships (Mutke et al. 2005). Although several theories have been advanced to explain the evolution of such masting behaviour, there is currently no consensus on its ultimate cause (Kelly 1994; Koenig et al. 1994). Research has shown, however, that during years of high seed production, most, if not all, mature trees within 


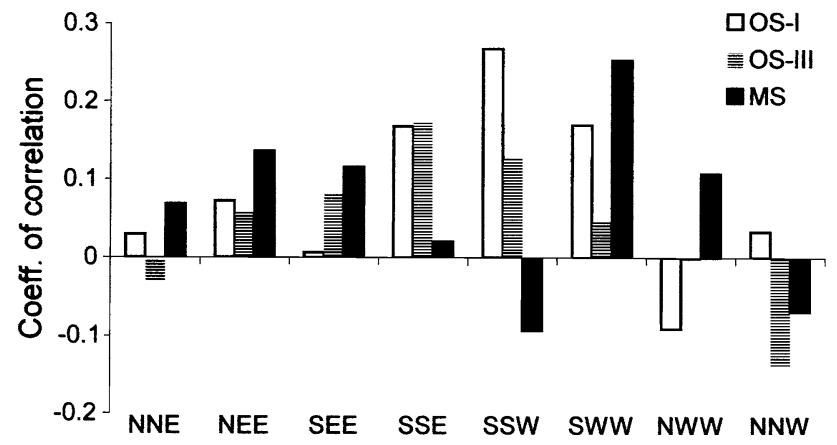

Fig. 4 Correlation coefficients between local basal area (BA3) in the azimuth sections and seed counts per seed trap cumulated over 2005-2007

the population reproduce (Silvertown 1980; Sork et al. 1993), creating an overall consistent spatial pattern of seed rain abundance between such years. However, in years of low seed production, only a subset of the dominant trees reproduce, creating a seed rain spatial pattern very different from that of mast years (and possibly different between non-mast years). For example, dispersion patterns of windgenerated seed rain in yellow birch (Betula alleghaniensis) varied over 4 years, showing some significant similarity in spatial patterns only in the 2 mast years in which most trees were fruiting (Houle 1998).

In the stands studied here, the annual seed density pattern exhibited some recurrence; that is, there was a positive correlation between the number of seeds collected from the same traps in consecutive years. In contrast to findings by Houle (1998), this positive dependence also occurred between the mast year of 2005 and the low seed-crop year of 2007 and, as the partial correlation coefficients show, held even when the effect of the local stand density was removed. Given that the sampled areas were located on relatively even slopes, it is unlikely that preferential deposition or retention of seeds on some micro-sites (e.g. on rougher surfaces or in concave terrain forms; Vander Wall and Joyner 1998) played any significant role in this positive inter-seasonal association of seed density. Likewise, as mentioned in the Methods section, the influence of seed predators in the stands studied may be disregarded. Instead, this association might be partly explainable by the recurrent fruiting of certain trees, for example, those of a dominant social position. In a population of red oak (Quercus rubra) surveyed by Healy et al. (1999), for
Fig. 5 Simulation envelopes for the variance-to-mean ratio (dashed line) and the variation coefficient of seed density (solid line) dependent on mother tree density, dispersal distance, seed output, seed shadows shape and the number of consecutive seed fall seasons (cumulative seed density). In each case, only one variable was changed, while the others were held constant at the following settings: seed production $=5$ seeds per $\mathrm{cm}^{2}$ of basal area, $\beta_{0}=15 \mathrm{~m}$, $\beta_{1}=2$ and the number of mother trees $=250$ per ha. More details on the simulation procedure are given in Methods section
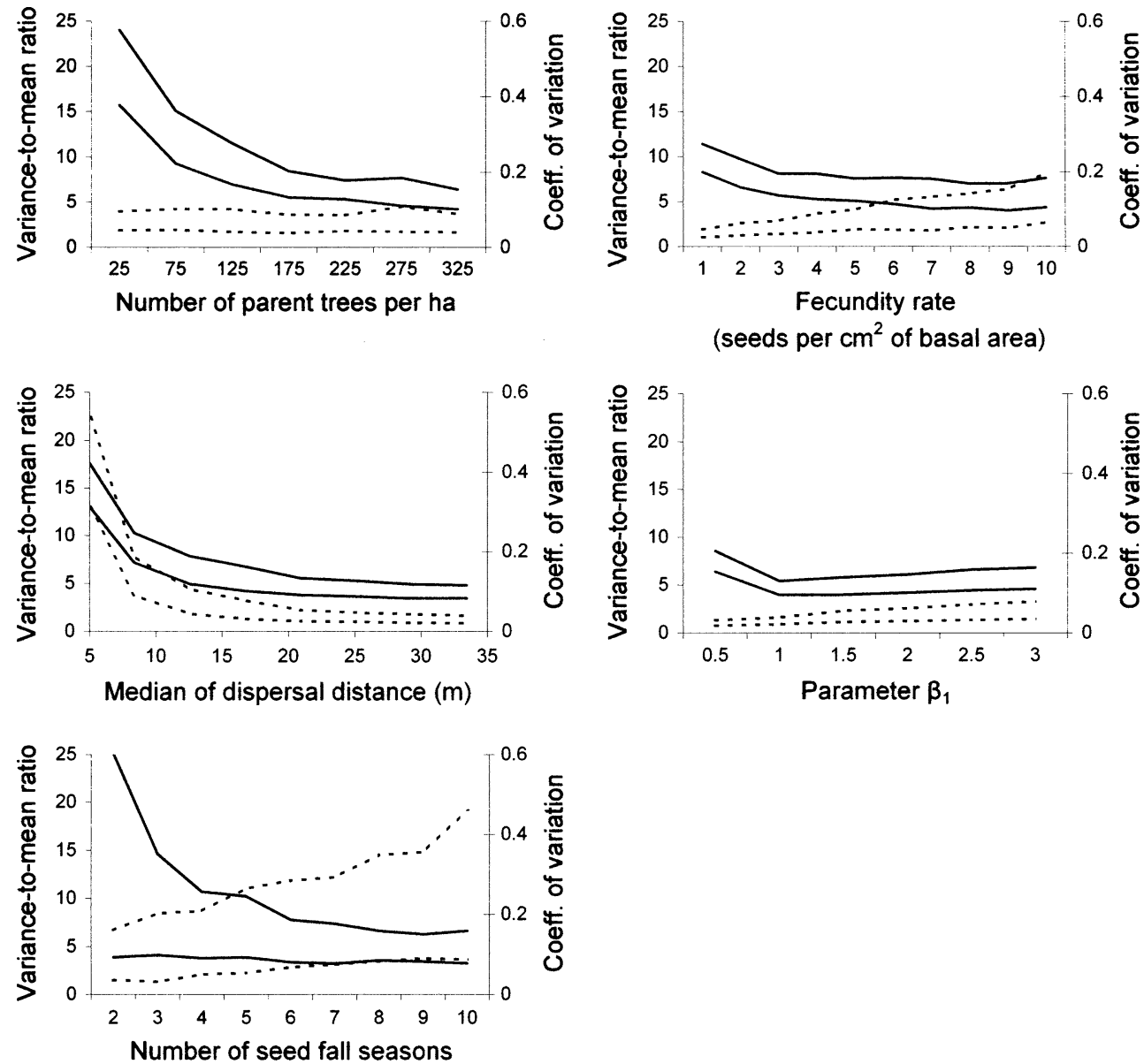
Fig. 6 Simulation envelopes for the ratio of small-scale variation to large-scale variation of seed density dependent on mother trees density, dispersal distance, seed outputs and seed shadows shape. In each case, only one variable was changed, while the others were held constant at the following settings: seed

production $=5$ seeds per $\mathrm{cm}^{2}$ of basal area, $\beta_{0}=15 \mathrm{~m}$, the $\beta_{1}=2$ and number of mother trees $=250$ per ha. The lower the ratio of small-scale to largescale variation, the stronger the spatial dependence in the data
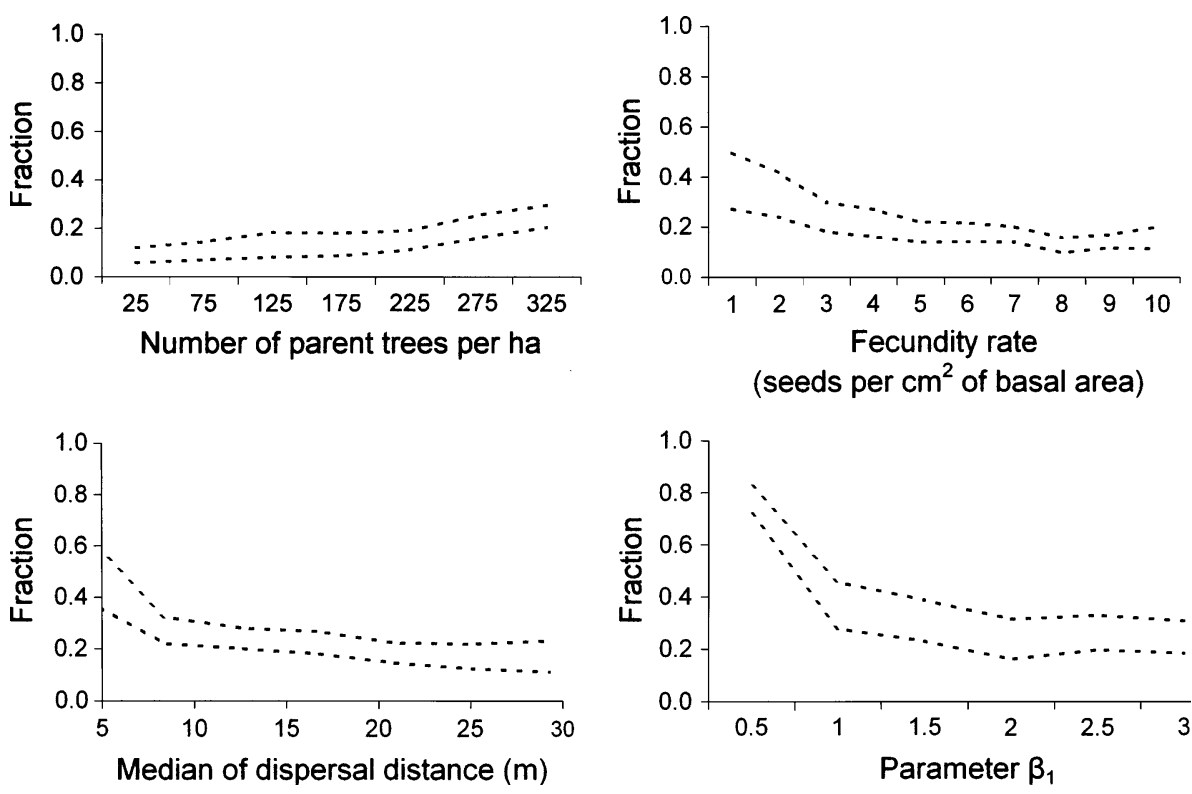

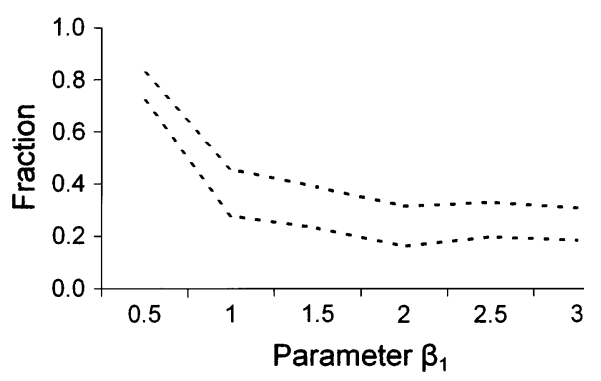

instance, better-than-average acorn producers tended to produce acorns in most of 11 years. Likewise, Greenberg (2000), in an analysis of a population of dominant and codominant trees of good form that could reasonably be expected to produce seeds, found that good producers produced acorns more frequently and had more acorns $/ \mathrm{m}^{2}$ of basal area on fruiting trees than did poor producers.

The strong spatial dependence of seed density emerged in both the empirical and the simulated data (Fig. 6), indicating that the arrangement of mother trees and variation in their basal area-related fecundity were sufficient to evoke an effect of spatial dependence on seed density. Moreover, based on the simulation experiment, it may be assumed that, even though relatively convex seed shadows appear important, spatial dependence also intensifies under the conditions of a small number of mother trees, high seed outputs and longer dispersal distances. To some extent, these assumptions correspond with the empirical results: spatial dependence was stronger in years of high seed production and in the one-storeyed OS-I and OS-III stands, where wind speeds in the dense crown zone were probably lower and the seed shadows more convex. Conversely, the weakness (in 2006) or complete absence (in 2005 and 2007) of spatial dependence in the MS stand may have resulted from its very heterogeneous vertical structure, higher wind speeds in the loose canopy zone and more concave seed shadows.

In the stands studied, the number of fallen seeds was positively correlated with local stand density measures, although the relations, perhaps except for the OS-I stand, were weak. This positive relation may stem from a greater probability to happen on trees producing seeds in more dense (but not over-densed) stand patches, more effective trapping of seeds in denser canopies and a probably slower and more turbulent wind flow that might decrease dispersal distances. However, the individual contribution of each of these factors remains an open question. The better performance of the basal area-based index over the tree numberbased index was not unexpected in that it confirms the well-known rule that larger trees of dominant social position produce more seeds than smaller over-topped trees (Greene et al. 2002; Greenberg 2000; Sirois 2000; Turner et al. 2007). For example, Clark et al.'s (1999) modelling study of Abies concolor tree identified an increase in fecundity of 3.2 for each $\mathrm{cm}^{2}$ of basal area and Sagnard et al. (2007), using similar inverse modelling approaches for Abies alba, obtained 4.75 and 10.0, respectively, for 2 consecutive years. Calogeropoulos et al. (2003) found that substituting basal area for cone production as a proxy for seed output only insignificantly (by $\sim 5 \%$ ) increased the explained variation in ground seed density for Abies balsamea. Nevertheless, basal area alone seems an insufficient predictor of individual fecundity. For instance, although Sagnard et al.'s (2007) study of Abies alba identified a significant linear correlation between the number of cones and tree basal area, this relation explained less than $50 \%$ of the total variation. Dohrenbusch (1997) found that for Pinus sylvestris trees seed output correlated more strongly with the number of whorls than with basal area or crown length. Clearly, then, there is a need for intensive study of this issue.

Whereas the exponential or log-normal weight functions (in the OS-I stand) or canopy openness (in the OS-III stand) yielded better results for single stands in terms of the seed density predictors tested, the most reliable results across all stands were given by local basal area calculated for a radius equal to about 3 times the nearest-neighbour distance. This radius (i.e. $6.5-10.5 \mathrm{~m}$ in the stands studied), although it may seem rather short compared to the median dispersal 
distance estimated by Sagnard et al. (2007, e.g. 13.2-19.4 m), corresponds well with as yet unpublished results obtained by the author (a median dispersal distance of between 5.6 and 14.7 depending on wind speed, stand density and the height from which the seeds were dropped). Moreover, this short distance may reflect the fact that in stands whose spatial patterns deviate little from random, the neighbourhoods of randomly picked points differ mostly on a small spatial scale. For example, for the OS-I, OS-III and MS stands studied here, the coefficient of variation for the BA1 index was 1.13, 0.69 and 2.67, respectively, decreased exponentially as the radius increased and for the BA5 index was only $0.16,0.15$ and 0.25 , respectively.

Using distance-weighted indices yielded acceptable results only for the OS-I stand, for which both the exponential and log-normal models performed significantly better than the Poisson model. It is worth noting, however, that these weight functions are more platykurtic than those used by Sagnard et al. (2007). For example, the 20 and 60 quartiles for the exponential model fitted here (INVexp) are 3 and $7 \mathrm{~m}$, respectively, as opposed to 8 and $26 \mathrm{~m}$ in Sagnard et al.'s model (INVmod). Nevertheless, applying Sagnard et al.'s (2007) model to both the 2005-2007 data and those for the mast year of 2005 (not reported here) in which almost all firs produced seeds decreased prediction accuracy considerably. These discrepancies confirm the limited generality of phenomenological models of seed dispersal. Nevertheless, the finding that trees make different contributions depending on their location with reference to the direction of dominant winds suggests that the dispersal models could be strengthened by the integration of a directional variable (see Wagner et al. 2004 and Wälder et al. 2009 for suggested methodological approaches).

Accurate calibration of seed dispersal models requires the proper arrangements of seed traps (Stoyan and Wagner 2001). That is, far-away traps are crucial for estimating long dispersal tails, whereas traps nearest to the mother tree are helpful in choosing appropriately between a lognormal model (in which the mode of seed density per area unit falls some distance from the tree) and a monotonously decreasing alternative. Obviously, the strongly overlapping seed shadows in the stands studied here could result in underestimation of the effects of long-distance dispersal. Therefore, as already pointed out, the kernel functions used here are more like weight functions than true dispersal kernels that aim to describe "real" seed shadows based on known parent tree locations and observed seed counts.

\section{Concluding remarks}

In sum, the seed density distributions under conditions of strongly overlapping seed shadows, rather than corresponding to the Poisson model, were characterised by over-dispersion, and the deviations from the Poisson distribution were larger for seed density cumulated over 3 years than for the densities from single seasons. The simulation study also showed that random seed rain may occur only in the presence of concave seed dispersal curves, considerable dispersal distances and low fecundity rates. There was also evidence of strong spatio-temporal correlation of seed density that is probably attributable to the arrangement of mother trees and the variation in their seed outputs. Indeed, linking fecundity rate with the basal area of mother trees was seemingly sufficient to evoke an effect of strong spatial dependence on density patterns, even under conditions of strongly overlapping seed shadows. In the majority of cases, seed density was positively correlated with the local stand density indices, although the effect of this factor was considerably weaker than that of spatial correlation. Overall, the results suggest that even in relatively homogenous stands, seed rain can be expected to exhibit considerable spatial heterogeneity.

Acknowledgments The authors gratefully acknowledge the financial support of this research by the Polish Ministry of Science and High Education (project No. 2 P06L 017 28, contract No. 0816/P06/ 2005/28). They would also like to thank three anonymous referees for valuable comments and improving the manuscript in terms of coherence and exposition.

Open Access This article is distributed under the terms of the Creative Commons Attribution Noncommercial License which permits any noncommercial use, distribution, and reproduction in any medium, provided the original author(s) and source are credited.

\section{References}

Andersen M (1991) Mechanistic models for the seed shadows of wind-dispersed seeds. Am Natur 137:476-497

Burschel P, El Kateb H, Huss J, Mosandl R (1985) Die Verjüngung im Bergmischwald. Forstwiss Cbl 104:65-100

Calogeropoulos C, Greene DF, Messier C, Brais S (2003) Refining tree recruitment models. Can J For Res 33:41-46

Clark JS, Macklin E, Wood L (1998) Stages and spatial scales of recruitment limitation in Southern Appalachian forests. Ecol Monogr 68:213-235

Clark JS, Silman M, Kern R, Macklin E, Hillerislambers J (1999) Seed dispersal near and far: patterns across temperate and tropical forests. Ecology 80:1475-1494

Cressie NAC (1991) Statistics for spatial data. Willey, New York

Diggle PJ (1983) Statistical analysis of spatial point patterns. Academic Press, London

Dobosz M (2004) Wspomagana komputerowo statystyczna analiza wyników badań. Akademicka Oficyna Wydawnicza Exit, Warszawa

Dohrenbusch A (1997) Die natürliche Verjüngung der Kiefer (Pinus sylvestris L.) im nordwestdeutschen Pleistozän. Schriftenr Forstl Fakult Univ Göttingen 123:3-269

Efron B, Tibshirani RJ (1993) An introduction to the bootstrap. Chapmann \& Hall/CRC, New York 
Greenberg CH (2000) Individual variation in acorn production by five species of southern Appalachian oaks. For Ecol Manage 132: $199-210$

Greene DF, Calogeropoulos C (2002) Measuring and modelling seed dispersal of terrestrial plants. In: Bullock JM, Kenward RE, Hails RS (eds) Dispersal ecology. Blackwell Publishing, Malden, pp 3-23

Greene DF, Johnson EA (1989) A model of wind dispersal of winged or plumed seeds. Ecology 70:339-347

Greene DF, Johnson EA (1996) Wind dispersal of seeds from a forest into a clearing. Ecology 77:595-609

Greene DF, Messier C, Asselin H, Fortin MJ (2002) The effects of light availability and basal area on cone production in Abies balsamea and Picea glauca. Can J Bot 80:370-377

Guevara S, Laborde J (1993) Monitoring seed dispersal at isolated standing trees in tropical pastures: consequences for local species availability. Vegetatio 107(108):319-338

Healy WM, Lewis AM, Boose EF (1999) Variation of red oak acorn production. For Ecol Manage 116:1-11

Hess M (1965) Piętra klimatyczne w polskich Karpatach Zachodnich. Zesz Nauk UJ, 115. Pr geogr 11:1-258

Holthuijzen AMA, Sharik TL (1985) The red cedar (Juniperus virginiana L.) seed shadow along a fenceline. Am Mid Nat 113:200-202

Houle G (1998) Seed dispersal and seedling recruitment of Betula alleghaniensis: spatial inconsistency in time. Ecology 79: 807-818

Johnson WC (1988) Estimating dispersibility of Acer, Fraxinus, and Tilia in fragmented landscapes from patterns of seedling establishment. Landsc Ecol 1:175-187

Kelly D (1994) The evolutionary ecology of mast seeding. Trends Ecol Evol 9:465-470

Koenig WD, Mumme RL, Carmen WJ, Stanback MT (1994) Acorn production by oaks in central coastal California: variation within and among years. Ecology 75:99-109

Kohlermann L (1950) Untersuchungen über die Windverbreitung der Früchte und Samen mitteleuropäischer Waldbäume. Forstwiss Cbl 69:606-624

Kuparinen A (2006) Mechanistic models for wind dispersal. Trends Plant Sci 11:296-301

Lorenc H (2005) Atlas klimatu Polski. IMGiW, Warszawa

Mutke S, Gordo J, Gil L (2005) Variability of Mediterranean Stone pine cone production: yield loss as response to climate change. Agric For Meteorol 132:263-272

Nathan R, Muller-Landau HC (2000) Spatial patterns of seed dispersal, their determinants and consequences for recruitment. Trends Ecol Evol 15:278-285
Nathan R, Safriel UN, Noy-Meir I (2001) Field validation and sensitivity analysis of a mechanistic model for tree seed dispersal by wind. Ecology 82:374-388

Nuttle T, Haefner JW (2005) Seed dispersal in heterogeneous environments: bridging the gap between mechanistic dispersal and forest dynamics models. Am Nat 165:336-349

Ribbens E, Silander JA, Pacala SW (1994) Seedling recruitment in forests: calibrating models to predict patterns of tree seedling dispersion. Ecology 75:1794-1806

Rohmeder E (1972) Das Saatgut in der Forstwirtschaft. Parey, Hamburg

Sagnard F, Pichot Ch, Dreyfus Ph, Jordano P, Fady B (2007) Modelling seed dispersal to predict seedling recruitment: recolonization dynamics in a plantation forest. Ecol Model 203:464-474

Schippers P, Jongejans E (2005) Release thresholds strongly determine the range of seed dispersal by wind. Ecol Model 185:93-103

Silvertown JW (1980) The evolutionary ecology of mast seeding in trees. Biol J Linn Soc 14:235-250

Sirois L (2000) Spatiotemporal variation in black spruce cone and seed crops along a boreal forest tree line transect. Can J For Res 30:900-909

Sork VL, Bramble J, Sexton O (1993) Ecology of mast-fruiting in three species of North American deciduous oaks. Ecology 74:528-541

Stanisz A (2007) Przystępny kurs statystyki z zastosowaniem Statistica PL na przykładach z medycyny. Tom 2. Modele liniowe i nieliniowe, Statsoft, Kraków

Stoyan D, Wagner S (2001) Estimating the fruit dispersion of anemochorous forest trees. Ecol Model 145:35-47

Suszka B (1983) Rozmnażanie generatywne. In: Bialobok S (ed) Jodła pospolita-Abies alba Mill. Monografie popularno-naukowe „Nasze drzewa leśne”, Tom 4:175-265

Turner MG, Turner DM, Romme WH, Tinker DB (2007) Cone production in young post-fire Pinus contorta stands in greater Yellowstone (USA). For Ecol Manage 242:119-126

Vander Wall SB, Joyner JW (1998) Secondary dispersal by the wind of winged pine seeds across the ground surface. Am Midl Nat 139:365-373

Wagner S, Wälder K, Ribbens E, Zeibig A (2004) Directionality in fruit dispersal models for anemochorous forest trees. Ecol Model 179:487-498

Wälder K, Näther W, Wagner S (2009) Improving inverse model fitting in trees-anisotropy, multiplicative effects, and bayes estimation. Ecol Model 220:1044-1053 